\title{
ROLE OF MULTIDETECTOR CT IN IMAGING OF LYMPHOMA
}

Shivraj Marotirao Ingole1, Reshma Prakash Chavan², Tushar Madhavrao Kalekar3, Prashant G. Pote4, Shilpa V. Domkundwar5, Sharad M. Malvadhkar6, Sharad B. Ghatge ${ }^{7}$, Varsha Pratik Rathi ${ }^{8}$

\begin{abstract}
${ }^{1}$ Associate Professor, Department of Radiology, GMC and Sir J. J. Group of Hospitals, Mumbai. ${ }^{2}$ Associate Professor, Department of Otorhinolaryngology, Dr. V. M. Medical College, Solapur. ${ }^{3}$ Associate Professor, Department of Radiology, Dr. D. Y. Patil Medical College, Pune. ${ }^{4}$ Senior Resident, Department of Radiology, GMC and Sir J. J. Group of Hospitals, Mumbai. 5 Professor and HOD, Department of Radiology, GMC and Sir J. J. Group of Hospitals, Mumbai. ${ }^{6}$ Associate Professor, Department of Radiology, GMC and Sir J. J. Group of Hospitals, Mumbai. ${ }^{7}$ Associate Professor, Department of Radiology, GMC and Sir J. J. Group of Hospitals, Mumbai. sProfessor, Department of Radiology, GMC and Sir J. J. Group of Hospitals, Mumbai.
\end{abstract}

\section{ABSTRACT}

\section{BACKGROUND}

Lymphomas are one of the common neoplasms of the patients in the young age group. Accurate staging of the patients is very important in planning appropriate therapy.

\section{MATERIALS AND METHODS}

The study was a retrospective survey from 2004 to 2005. CT scan abdomen was performed in 80 patients of histological proved lymphoma. CT guided fine needle aspiration cytology were also performed where indicated by the referring physician.

\section{RESULTS}

In this retrospective male preponderance study of 80 patients with proven lymphoma, positive findings were seen in 57 (71.2\%) patients with $46 \%$ of HD and $84 \%$ of NHL patients showed intra-abdominal involvement. CT accurately detected nodal and extra nodal sites of involvement. Lymph node involvement was the most common manifestation of lymphoma and it was seen in $66 \%$ of all the patients. CT showed the exact sites, the pattern of involvement, the morphological features and associated complications. In both HD and NHL. Extranodal involvement was detected in patients. The involvement of liver was seen in $28 \%$, spleen in $26.3 \%$, GIT in $14 \%$ and renal involvement was seen in $7 \%$ of the patients with positive findings. Other sites of involvement include pancreas, psoas muscle and vertebrae.

\section{CONCLUSION}

The accuracy of CT in the staging of patients with lymphoma is widely recognised, and it is now the first investigation of choice in the initial staging and followup of these patients. Most centres now rely on biopsy of one group of nodes for diagnosis and stage the patient based on imaging with CT and haematological assessment including bone marrow biopsy.

\section{KEYWORDS}

Lymphoma, Lymphoma Staging, Lymph Node, Computed Tomography.

HOW TO CITE THIS ARTICLE: Ingole SM, Chavan RP, Kalekar TM, et al. Role of multidetector CT in imaging of lymphoma. J. Evolution Med. Dent. Sci. 2017;6(27):2264-2269, DOI: 10.14260/Jemds/2017/487

\section{BACKGROUND}

Lymphomas are malignant tumours of lymphoreticular origin, i.e. from lymphocytes and histiocytes and their precursor cells. Clinically and pathologically, lymphomas are quite heterogeneous. However, two distinct clinical pathologic groups are routinely distinguished; Hodgkin's Disease (HD) and Non-Hodgkin's Lymphoma (NHL).(1)

They are one of the common neoplasms of the patients in the young age group.

Financial or Other, Competing Interest: None.

Submission 10-02-2017, Peer Review 19-03-2017,

Acceptance 23-03-2017, Published 03-04-2017.

Corresponding Author:

Dr. Shivraj Marotirao Ingole,

Flat No 4,

Swastik Building,

Sir J. J. Hospital Campus,

Byculla,

Mumbai-08.

E-mail: drshivraj@gmail.com

DOI: $10.14260 /$ jemds $/ 2017 / 487$

(c) (1) $(9)$
Accurate staging of the patients is very important in planning appropriate therapy, as advent of newer chemotherapeutic regimens and radiotherapy planning has improved the outcome with aim of achieving total cure rather than palliative cure. A series of examinations were performed for this purpose.

In the past, lymphography was performed as primary investigation to assess the retroperitoneal lymphadenopathy.(2) It is highly accurate in the detection of macroscopic nodal abnormalities. The limitations are few, although the nodes above cisterna chyli in the root of mesentery and in the hepatic or splenic hili are not demonstrated. Exploratory laparotomy was undertaken to further stage patients when bone marrow biopsy did not reveal any tumour.(3) Ultrasound is a useful survey technique for bulky retroperitoneal lymphadenopathy and can also detect isolated enlarged nodes or groups of nodes in the other areas. But main disadvantages are the operator dependency and suboptimal evaluation due to excessive bowel gases and obesity.(4) Computed Tomography (CT) is a more accurate method in this regard and in addition 
lymphomatous involvement of other abdominal viscera including liver, spleen, gastrointestinal tract, genitourinary system can be detected earlier.

It presents a cross-sectional picture of the abdomen, which can be used in planning of radiation therapy ports. So CT forms an essential component of staging procedure.(1,5,6) Administration of oral contrast prior to CT scan allows good visualisation of the bowel loops and separates them from retroperitoneal and mesenteric nodes as well as vessels. Intravenous administration of water soluble non-ionic contrast permits visualisation of vascular structures, which is essential to separate vessels from lymph nodes. Different patterns of enhancement, help in detection of lymphomatous deposits in the various abdominal organs.

CT is also the most acceptable and used modality for followup of patients with Lymphoma.

\section{Aims and Objectives}

1. To study the role of Multidetector CT in Imaging of Lymphoma.

2. To study the extent of involvement and characterisation of the morphology of the involved structures.

3. To study the differences of the involvement pattern and morphology among the different types of the lymphoma.

\section{MATERIALS AND METHODS}

The study was a retrospective survey from 2004 to 2005 . CT scan abdomen was performed in 80 patients of histological proved lymphoma; all the scans were performed in our Institution. The male-to-female ratio was 1.96:1; the age group ranging from years to years.

\section{Equipment}

The CT model used in the study was Siemens Somatom Definition 128 Slice CT Scanner, which is a third generation scanner. It is a fast scanner with short scan time. Slice thickness can be varied from 1 to $8 \mathrm{~mm}$. Images are acquired on a 512 x 512 pixel matrix. The detector system comprises of 512 solid-state cesium iodide devices. The tube and detectors are opposite each other and rotate continuously around the patient. The images stored on magnetic disc can be transferred to conventional film through Laser camera. The entire system operates at a temperature of 16 to 18 degrees Celsius.

\section{Technique}

Prior to the procedure, all patients are instructed to be fasting for $4 \mathrm{hrs} .800 \mathrm{~mL}$ of oral contrast is given to the patient over 45 minutes before the scan with another $200 \mathrm{~mL}$ just before taking the patient on for scanning.

Contiguous $8 \mathrm{~mm}$ thick plain scans with an interval of 10 $\mathrm{mm}$ are performed for the liver, followed by post contrast scan of $8 \mathrm{~mm}$ thickness at an interval of $10 \mathrm{~mm}$ from the domes of the diaphragm to the pubic symphysis. Thinner scans up to $4 \mathrm{~mm}$ are obtained whenever indicated.

CT guided fine needle aspiration cytology were also performed where indicated by the referring physician.

\section{RESULTS}

In the retrospective study of 80 patients with histological proven diagnosis of lymphoma were reviewed and the following data was obtained-

1. Total number of patients- 80
2. Total number of male patients- 53

3. Total number of female patients- 27

1. Male: Female ratio- 1.96: 1

4. Total no. of HD was 28 and Total no. of NHL were 52

5. Cases with Hodgkin's disease (Rye's Classification)- Total male patients were 19. Total female patients were 09 . Histopathology subtypes in HD were Lymphocyte predominance in 8 patients, Mixed Cellularity in 7 patients, Nodular sclerosis in 13 patients; while Lymphocyte depleted type was not found.

6. Cases with Non-Hodgkin's Lymphoma- Total male patients were 32. Total female patients were 20. Histopathology subtypes in NHL were Low grade in 19 patients, Intermediate grade in 14 patients and High grade in 18 patients.

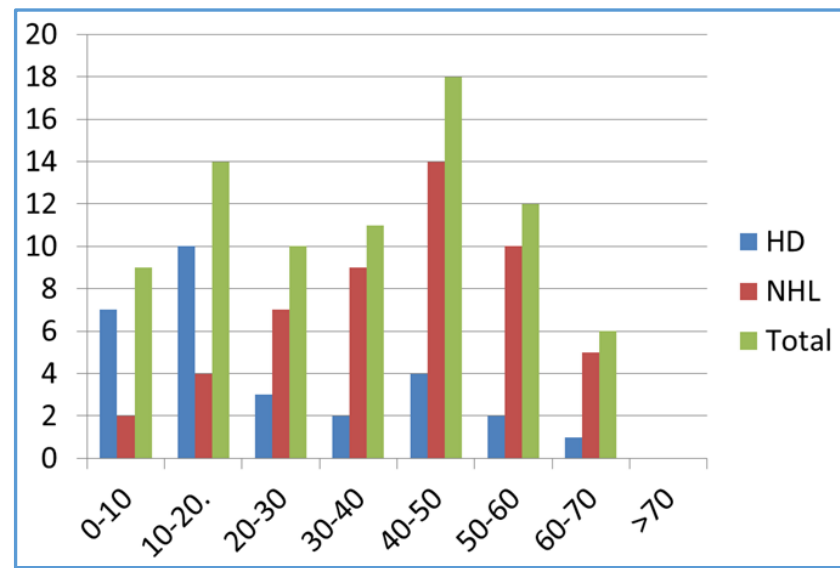

Age Distribution

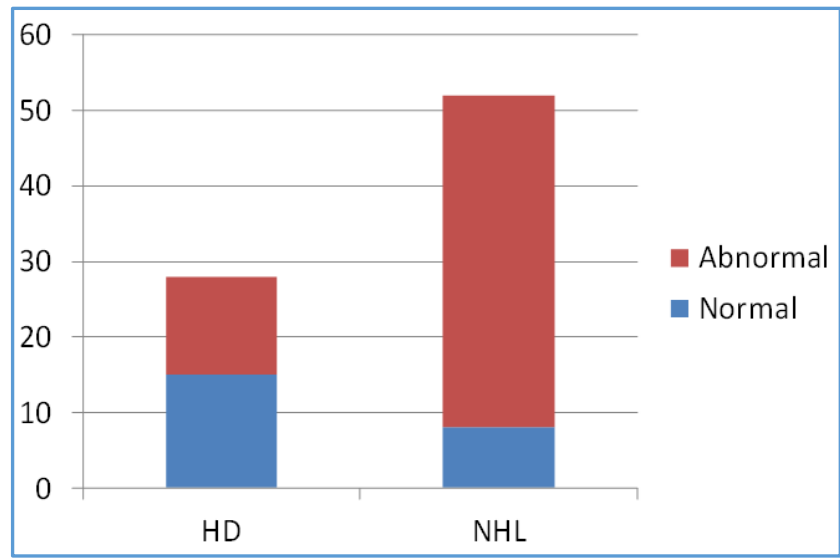

Findings at Initial CT Scan

\section{CT Findings in Hodgkin's Disease}

Total number of patients with lymphadenopathy $=8$. Total number of patients with extra nodal involvement $=5$. Size was less than $2 \mathrm{~cm}$ in 3 patients, between $2-4 \mathrm{~cm}$ in 3 patients and more than $4 \mathrm{~cm}$ in 2 patients. Enhancement was present in 2 patients. No enhancement was present in 4 patients. Total 2 patients showed necrotic lymph nodes. No lymph nodal calcification was seen in all HD patients. Total 5 patients showed involvement of spleen and liver. One patient showed involvement of kidney. 
Nodal Involvement

\begin{tabular}{|l|c|}
\hline \multicolumn{1}{|c|}{ Site } & Number of Cases \\
\hline Retroperitoneal & 18 \\
1. Paraaortic & 6 \\
2. Aortocaval & 6 \\
3. Precaval & 3 \\
4. Peripancreatic & 2 \\
5. Portal & 1 \\
\hline Mesenteric & 1 \\
\hline Iliac & 4 \\
\hline Others & 4 \\
\hline \multicolumn{2}{|c|}{ Table 1 } \\
\hline
\end{tabular}

\section{Extranodal Disease}

\begin{tabular}{|c|c|c|}
\hline $\begin{array}{c}\text { Organ } \\
\text { Involved }\end{array}$ & $\begin{array}{c}\text { Pattern of } \\
\text { Involvement }\end{array}$ & $\begin{array}{c}\text { No. of } \\
\text { Cases }\end{array}$ \\
\hline Spleen & Diffuse enlargement & 4 \\
\hline & $\begin{array}{c}\text { Focal lesions } \\
\text { lesions }\end{array}$ & 1 \\
\hline Liver & Diffuse enlargement & 4 \\
\hline & Focal lesions & 0 \\
\hline & $\begin{array}{c}\text { Diffuse enlargement with focal } \\
\text { lesions }\end{array}$ & 2 \\
\hline $\begin{array}{c}\text { Other Organ } \\
\text { Kidney }\end{array}$ & Diffuse enlargement of Kidney & 1 \\
\hline \multicolumn{2}{|c|}{ Table 2 } \\
\hline
\end{tabular}

CT Scan Findings in Patients of Non-Hodgkin's Lymphoma

Total number of patients with abdominal lymphadenopathy= 30. Total number of patients with extra nodal involvement= 37. Size was less than $2 \mathrm{~cm}$ in 10 patients, between $2-4 \mathrm{~cm}$ in 13 patients and more than $4 \mathrm{~cm}$ in 7 patients. Enhancement was present in 18 patients. No enhancement was present $=10$ patients. Total 11 patients showed necrotic lymph nodes. One patient showed lymph nodal calcification.

\section{Nodal Involvement}

Total number of patients with abdominal lymphadenopathy= 30 .

\begin{tabular}{|c|c|}
\hline Site & Number \\
\hline Paraaortic & 24 \\
\hline Preaortic & 18 \\
\hline Precaval & 20 \\
\hline Paracaval & 17 \\
\hline Retrocaval & 12 \\
\hline Celiac & 11 \\
\hline Peripancreatic & 10 \\
\hline Portal & 6 \\
\hline Mesenteric & 9 \\
\hline Retrocrural & 4 \\
\hline Iliac & 16 \\
\hline Obturator & 2 \\
\hline
\end{tabular}

\section{Extra Nodal Involvement}

\begin{tabular}{|c|c|c|}
\hline Organ Involved & Pattern of Involvement & No. of Cases \\
\hline \multirow[t]{3}{*}{ Spleen (Total 10) } & Diffuse enlargement & 5 \\
\hline & Focal lesions & 3 \\
\hline & $\begin{array}{l}\text { Diffuse enlargement with } \\
\text { focal lesions }\end{array}$ & 2 \\
\hline \multirow[t]{3}{*}{ Liver (Total 10) } & Diffuse enlargement & 5 \\
\hline & Focal lesions & 2 \\
\hline & $\begin{array}{c}\text { Diffuse enlargement with } \\
\text { focal lesions }\end{array}$ & 3 \\
\hline GIT Involvement & \begin{tabular}{|l|} 
Stomach \\
\end{tabular} & 3 \\
\hline \multirow[t]{2}{*}{ (Total 8) } & Small Bowel & 3 \\
\hline & Large Bowel & 2 \\
\hline \multirow[t]{2}{*}{$\begin{array}{c}\text { GUT Involvement } \\
\text { (Total 3) }\end{array}$} & Renal Parenchymal & 2 \\
\hline & Perirenal Involvement & 1 \\
\hline \multirow[t]{5}{*}{ Others (Total 6) } & Pancreas & 1 \\
\hline & Muscle & 2 \\
\hline & Vertebrae & 1 \\
\hline & Peritoneum & 1 \\
\hline & Adrenal & 1 \\
\hline \multicolumn{3}{|c|}{ Table 4} \\
\hline
\end{tabular}

\section{DISCUSSION}

In this study of 80 patients, the age group ranged from 3 years to 78 years. The peak incidence of HD was in second decade with 10 patients $\{35.7 \%\}$. There is second small peak observed in the fourth decade with 4 patients $(14.2 \%)$. So there is bimodal peak observed in the second and fourth decade. The peak incidence of NHL in the series was in fifth decade with 14 patients in this age group (29.6\%). This corroborates with the age related incidence of lymphoma in the literature (Freedman et al(7)). There was male predominance in the study (male-to-female ratio was 1.96:1). 28 cases of HD and 52 cases of NHL were studied in the study. The commonest histological subtype of HD was nodular sclerosis accounting for $46.4 \%$ of the cases. The commonest type of NHL in the study was - In $57(71.2 \%)$ of the 80 patients, the initial CT scan of abdomen showed evidence of involvement by lymphoma at one or more sites. In 23 patients CT scan showed normal findings $(28.7 \%)$. The CT scan was normal in 15 out of 28 patients of HD (53.5\%) and it was normal in only 8 patients of NHL (15.3\%). The commonest abnormality found was enlarged lymph nodes (66.6\%). These findings are consistent with the previous literature studies showing that the abdominal involvement is more common in Non-Hodgkin's lymphoma than HD.

\section{Lymph Nodes}

Abdominal lymph node enlargement ( $>10 \mathrm{~mm}$ in diameter, $>$ $6 \mathrm{~mm}$ retrocrural and $>15 \mathrm{~mm}$ pelvic) was initially present in $38(66.6 \%)$ of the 57 patients with evidence of positive findings. Enlarged nodes were seen in the upper abdomen only (from diaphragm to aortic bifurcation) in 14 patients, in the abdomen and pelvis in 24 patients and in the pelvis in 6 patients. Enlarged nodes in the abdomen and pelvis are seen in 22 out of 30 patients of NHL and in only 2 out 8 cases of HD. This is consistent with the literature studies that NHL $(6,8,9)$ shows wide spread involvement as compared to HD, which presents as localised disease; 8 out of 28 patients of 
HD (28.5\%) as compared to 30 patients out of $52(57.7 \%)$ of NHL. These finding are consistent with Castellino R A et al,(9) who showed $24 \%$ of HD and $48 \%$ of NHL showed retroperitoneal lymph node involvement. The mesenteric involvement was seen in only 1 out of $28(3.5 \%)$ cases of HD as compared to 9 out of $52(17.3 \%)$ cases of NHL. These findings were similar to Blackledge and Castellino et al $(5,9)$ who showed that mesenteric lymph node involvement was more common in NHL than HD. Also, the involvement of the different nodal sites like portal, peripancreatic and celiac which was seen predominantly in NHL. The retrocrural, splenic and renal hilar enlargement was seen only in NHL cases.

In 20 of the 38 patients with nodal enlargement, CT scan showed evidence of lymphomatous involvement of one or more of the following sites, GI tract (4 patients), liver (10 patients), spleen (10 patients) and omentum (1 patient). In one patient, the only extra nodal site of involvement was the epidural space; 5 out of 8 patients of HD and 15 out of 30 patients of NHL with lymph node involvement show extra nodal involvement.

The involvement of the retroperitoneal lymph nodes in para-aortic region was most common; it was seen in 30 patients out of 38 who showed lymph node involvement $(78.9 \%)$. It was seen equally common in both HD (75\%) and NHL (80\%). In 13 patients with enlarged abdominal lymph nodes, the diameter of the largest node was up to $2 \mathrm{~cm}$ (34.2\%), $2-4 \mathrm{~cm}$ in 18 patients (47.3\%) and $4-10 \mathrm{~cm}$ or more in 7 patients $(18.4 \%)$.

In $24(63.1 \%)$ of the 38 patients all nodes were homogeneous, usually denser than the muscle. In 13 patients $(34.2 \%)$, the nodes had central low density. The nodes with central necrosis ranged in diameter from 4 to 10 . In one patient, there was evidence of calcification. Evidence of necrosis is seen in 11 out of 30 cases (36.6\%) of NHL showing lymph node involvement as compared to only 2 out of 8 in patients of HD (25\%). This showed that the evidence of necrosis is more common in bulky nodes and so in NHL cases than HD who showed smaller and homogeneous nodes.

Calcification in patients with lymphoma occurring before therapy is rare as opposed to that in lymphoma after therapy. It occurred in our patients more often in the mediastinum, in patients with non-Hodgkin's lymphoma rather than in patients with Hodgkin's lymphoma and only in patients with the aggressive type of disease.

\section{Liver}

In this study, the involvement of liver by lymphoma was seen in 16 cases $(20.0 \%)$ out of 80 in the form of diffuse enlargement and/or focal lesions. These results were comparable to the study of Zoronza et al(10) who have found hepatic involvement in $11.5 \%$ of cases. Diffuse enlargement with or without focal lesions is seen in 16 patients with positive findings (28.0\%). Diffuse enlargement without focal lesions is seen in 9 patients (15.7\%). Focal lesions, varying in size from solitary to multiple were seen in 9 out of 57 patients with positive findings (15.7\%). In all cases, the focal lesions were less dense than the liver parenchyma. Only 5 patients show focal lesions without evidence of enlargement (8.7\%). In the absence of focal lesions, the enlargement of the liver was mild (liver span less than $18 \mathrm{~cm}$ ). In 4 of 80 patients with focal lesions showed marked hepatomegaly (more than
$18 \mathrm{~cm}$ ); 6 out of 28 cases of HD showed hepatic involvement (21.4\%) as compared to 10 out of 52 patients with NHL (19.2\%). Diffuse enlargement without focal lesions is seen in $4(50 \%)$ patients of HD with hepatic involvement as compared to $3(33.3 \%)$ of NHL cases.

Out of 16 cases with hepatic involvement by lymphoma also showed splenic involvement in 12 cases (75\%). This correlates with the study of Strijk et al,(11) where the involvement of the liver was always accompanied by splenic disease.

In 11 out of 16 (68.7) patients with liver involvement showed evidence of lymphadenopathy. In one patient, there was associated IHBR dilatation due to portal adenopathy.

\section{Spleen}

Splenic involvement was seen in 15 (18.75\%) out of 80 and $26.3 \%$ of all the patients with positive abdominal findings, with 9 patients showing enlargement only without evidence of any focal lesions; 2 patients showed focal lesions with splenomegaly. Focal splenic lesions were seen in patients that varied from solitary to multiple in numbers.

These results were comparable to the study of Castellino et al that showed splenic abnormalities with CT in $14 \%$ of cases and Pond et al 35 detected splenic abnormalities in $15.1 \%$ of the cases. Previous studies have shown that the detection of splenic disease by CT is difficult due to the military pattern of involvement.

Splenic involvement was seen in $5(17.8 \%)$ out of 28 cases of HD and 4 out of 5 patients showed diffuse enlargement without any focal lesion; 10 patients of NHL showed splenic involvement $(19.2 \%)$ and only 3 patients showed diffuse enlargement and focal lesions are seen in 5 patients. The degree of splenic enlargement was mild (12 - 15 $\mathrm{cm})$ in 5 patients and moderate in 4 patients $(15-20 \mathrm{~cm})$. In all the 4 patients with moderate splenomegaly, there is associated hepatomegaly.

In 12 patients $(80 \%)$ with splenic involvement, there is associated lymph node involvement.

\section{Kidney}

The CT scan showed evidence of renal involvement by lymphoma in $4(5 \%)$ of all the patients and in 3 cases there was evidence of diffuse renal lymphoma seen. In one patient, there are focal lesions. The results are comparable to Cohan et al 14 who found $7 \%$ incidence of renal involvement in malignant lymphoma.

The renal nodules were less dense than the adjacent renal parenchyma on post contrast scans; 3 out of 4 patients (75\%) were of NHL and 1 patient of HD showed diffuse enlargement of both kidneys.

In all the patients with renal lesions, CT scan showed other sites of extra nodal involvement. Perirenal lymphomatous involvement was seen in one patient of NHL.

The GIT involvement was seen in $8(10 \%)$ of the CT scans. Sites of involvement included the stomach, $3(37.5 \%)$ patients followed by small intestine (ileocaecal region) in 3 cases $(37.5 \%)$ and the large bowel in 2 patients $(25 \%)$. The results were similar to the study of Lewin $\mathrm{K} \mathrm{J}$ et al,(12) who showed the stomach as the commonest site of GIT followed by small and large intestine and appendix. Megibow A J et al(13) also found similar results. All the patients were of diffuse non-Hodgkin's lymphoma and the age group ranged from 35 to 75 years. 
The CT findings showed circumferential wall thickening as commonest pattern in 6 cases. Focal eccentric wall thickening and a mass in 2 patients (ileocaecal region). This morphological pattern was similar to that described by Dodd et al,(14) who found circumferential wall thickening more than $1.5 \mathrm{~cm}$ in most of the patients.

In 5 of the 8 cases, CT also showed evidence of lymph node involvement (62.5\%) associated in 2 cases of focal lesions in the solid viscera. The results are comparable to the study of Buy et al,(15) who found associated lymphadenopathy in $92.5 \%$ of the patients.

\section{Pancreas}

Pancreatic involvement was seen in 2 patients (2.5\%), all of NHL type (3.5\% of NHL). All the cases showed extensive retroperitoneal and mesenteric lymphadenopathy.

The pattern of pancreatic involvement in the form of infiltration from adjacent lymph nodes in all the cases, correlates with the study of Glazer et al.(16,17,18)

\section{Peritoneum}

Ascites was seen in only one patient of the abdominal lymphoma cases. Omental and peritoneal infiltration was seen in 2 patients. All these patients were of NHL, high grade type and there was associated extensive retroperitoneal lymph node enlargement.

\section{Musculoskeletal Involvement}

CT showed lymphomatous involvement of the muscle in 2 patients $(2.5 \%)$. Marked enlargement of the psoas muscle with heterogeneous density was seen. In one patient, eccentric soft tissue infiltration of the epidural space of the lumbar spine was observed. All the patients were of NHL high grade (3.4\%) and associated with extensive retroperitoneal lymphadenopathy and focal lesions were present in liver. The findings in our study correlate with that of Glazer et al, $(16,17,18)$ where the incidence of muscle involvement was $4 \%$. All the patients were having associated retroperitoneal lymphadenopathy.

Followup CT scan were available in 20 patients with 15 patients showing regression of the disease (75\%), 4 patients showed progression of the disease $(20 \%)$ and one patient showed no change in the disease status since the previous scan (5\%). The CT findings corroborated with clinical features in all the patients $(100 \%)$. These findings correlate with the study of Oliver et al(19) with CT scan showing an excellent correlation with clinical status of the patient.

Out of 4 patients with disease progression, two patients showed enlargement of the lymph node size and involvement of the other sites that were initially not involved and 2 patients showed deposits in the liver and spleen with enlargement of their size which was not seen initially.

All the patients with regression of the disease showed reduction of the lymph node size or disappearance of the lymph node mass and decrease in the attenuation of the lymph node and evidence of the calcification. Calcification after treatment was seen in 4 .
The patient with no change in the disease status was a case of HD and showed small lymph nodes in the upper retroperitoneum as were seen in the initial scan.

\section{CONCLUSION}

The accuracy of CT in the staging of patients with lymphoma is widely recognised, and it is now the first investigation of choice in the initial staging and followup of these patients.

Staging laparotomy involving splenectomy and biopsy of all lymph node sites was formerly gold standard for staging of intra-abdominal lymphoma, but is now rarely performed. Most centres now rely on biopsy of one group of nodes for diagnosis and stage the patient based on imaging with CT and haematological assessment including bone marrow biopsy.

In this retrospective male preponderance study of 80 patients with proven lymphoma, positive findings were seen in $57(71.2 \%)$ patients with $46 \%$ of $\mathrm{HD}$ and $84 \%$ of NHL patients showed intra-abdominal involvement. CT accurately detected nodal and extranodal sites of involvement.

Lymph node involvement was the most common manifestation of lymphoma and it was seen in $66 \%$ of all the patients. CT showed the exact sites, the pattern of involvement, the morphological features and associated complications like encasement of the vessels, hydronephrosis, biliary obstruction, bony erosion, extramedullary cord compression, etc. in both HD and NHL. Extranodal involvement was detected in patients. The involvement of liver was seen in $28 \%$, spleen in $26.3 \%$, GIT in $14 \%$ and renal involvement was seen in $7 \%$ of the patients with positive findings. Other sites of involvement include pancreas, psoas muscle and vertebrae.

So CT scan is the essential investigation modality in all patients with lymphoma, as it can detect the intra-abdominal disease.

\section{REFERENCES}

[1] Ganapathi KA, Pittaluga S, Odejide 00, et al. Early lymphoid lesions: conceptual, diagnostic and clinical challenges. Haematologica 2014;99(9):1421-32.

[2] Pond GD, Castellino RA, Horning $S$, et al. NonHodgkin's lymphoma: influence of lymphography, CT, and bone marrow biopsy on staging and management. Radiology 1989;170(1 Pt 1):159-64.

[3] Castellino RA, Hoppe RT, Blank N, et al. Computed tomography, lymphography, and staging laparotomy: correlation in initial staging of Hodgkin's disease. AJR Am J Roentgenol 1984;143(1):37-41.

[4] Creed L, Reger K, Pond GD, et al. Potential pitfall in CT and sonographic evaluation of suspected lymphoma. AJR Am J Roentgenol 1982;139(3):606-7.

[5] Blackledge G, Best JJ, Crowther D, et al. Computed tomography (CT) in the staging of patients with Hodgkin's disease: a report of 136 patients. Clin Radiol 1980;31(2):143-7.

[6] Bragg DG, Colby TV, Ward JH, et al. New concepts in non-Hodgkin lymphoma: radiologic implications. Radiology 1986;159(2):291-304.

[7] Nyberg DA, Jeffrey RB, Federle MP, et al. AIDS-related lymphomas: evaluation by abdominal CT. Radiology 1986;159(1):59-63. 


\section{Jemds.com}

[8] Jing BS. Diagnostic imaging of abdominal and pelvic lymph nodes in lymphoma. Radiol Clin North Am 1990;28(4):801-31.

[9] Castellino RA. Diagnostic imaging evaluation of Hodgkin's disease and non-Hodgkin's lymphoma. Cancer 1991;67(4 Suppl):1177-80.

[10] Zoronza J, Ginaldi S. Computed tomography in hepatic lymphoma. Radiology 1982;138:537-9.

[11] Strijk SP, Wagener DJ, Bogman MJ, et al. The spleen in Hodgkin disease: diagnostic value of CT. Radiology 1985;154(3):753-7.

[12] Lewin KJ, Ranchod M, Dorfman RF. Lymphomas of the gastrointestinal tract: a study of 117 cases presenting with gastrointestinal disease. Cancer 1978;42(2):693707.

[13] Megibow AJ, Balthazar EJ, Naidich DP, et al. Computed tomography of gastrointestinal lymphoma. AJR Am J Roentgenol 1983;141(3):541-7.

\section{Original Research Article}

[14] Dodd GD. Lymphoma of the hollow abdominal viscera. Radiol Clin North Am 1990;28(4):771-83.

[15] Buy JN, Moss AA. Computed tomography of gastric lymphoma. AJR Am J Roentgenol 1982;138(5):859-65.

[16] Aisen AM, Gross BH, Glazer GM, et al. Distribution of abdominal and pelvic hodgkin disease: implications for CT scanning. J Comput Assist Tomogr 1985;9(3):463-5.

[17] Heiken JP, Gold RP, Schnur MJ, et al. Computed tomography of renal lymphoma with ultrasound correlation. J Comput Assist Tomogr 1983;7(2):24550 .

[18] Jafri SZ, Bree RL, Amendola MA, et al. CT of renal and perirenal non-Hodgkin lymphoma. AJR Am J Roentgenol 1982;138(6):1101-5.

[19] Panicek M, Lautin JL, Castellino RA, et al. Non-Hodgkin lymphoma in skeletal muscle manifesting as homogeneous masses with CT attenuation similar to muscle. Skeletal Radiol 1997;26(11):633-5. 